\title{
Processamento e caracterização de snack extrudado a partir de farinhas de quirera de arroz e de bandinha de feijão
}

\author{
Processing and characterization of an extruded snack made \\ from broken rice flour and broken common bean flour
}

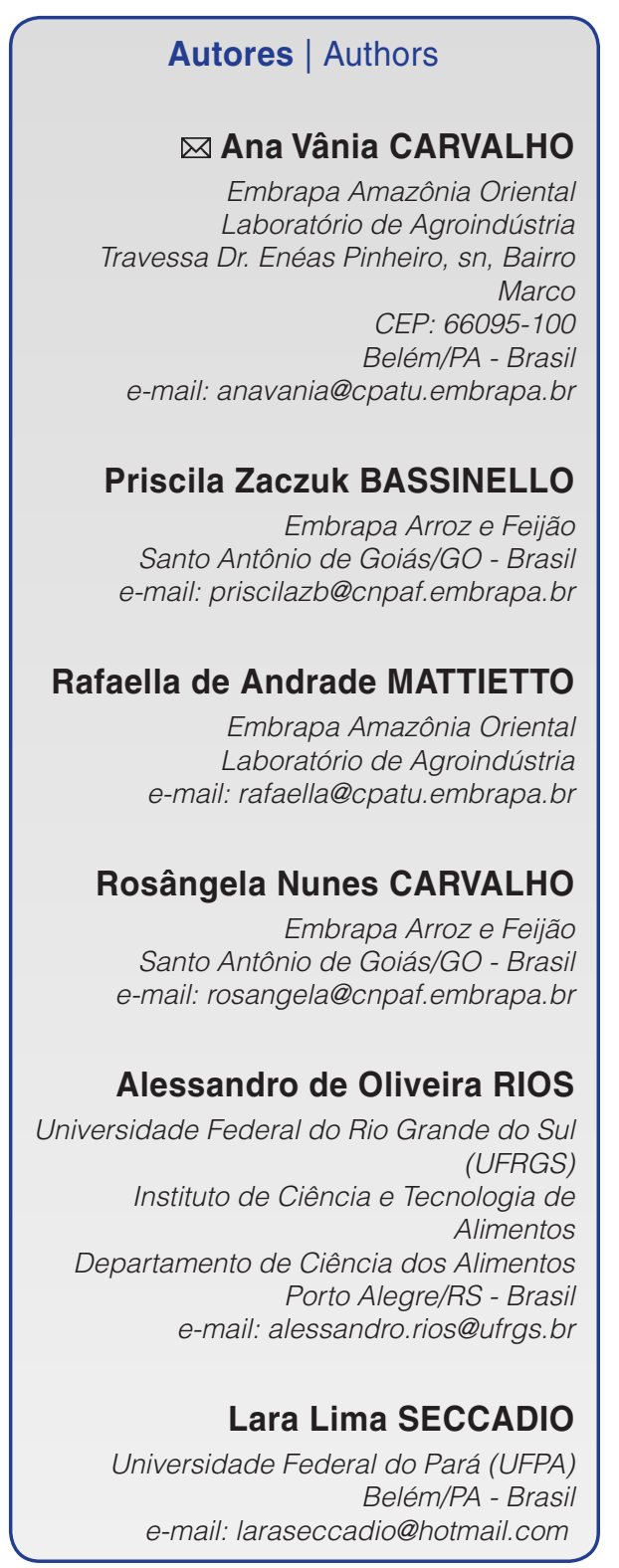

$\triangle$ Autor Correspondente / Corresponding Author

Recebido / Received: 22/12/2010 Aprovado / Approved: 06/09/2011 Publicado / Published: mar./2012

\section{Resumo}

Este trabalho teve por objetivo desenvolver nova formulação de snack por extrusão termoplástica a partir de mistura de farinhas de quirera de arroz e de bandinha de feijão, bem como avaliar o potencial nutricional, tecnológico e sensorial do novo produto. A farinha de bandinha de feijão carioca foi incorporada à farinha de quirera de arroz na proporção de 30\%. O snack foi produzido em extrusora monorrosca, escala piloto. Os parâmetros de extrusão foram fixos, utilizando-se três zonas de extrusão com temperaturas de 40, 60 e $85^{\circ} \mathrm{C}$; velocidade do parafuso de $177 \mathrm{rpm}$; taxa de alimentação de $292 \mathrm{~g} \cdot \mathrm{min}^{-1}$, e matriz circular de $3,85 \mathrm{~mm}$ de diâmetro. A amostra de snack foi submetida a caracterizações fisicoquímica, tecnológica e sensorial. Observou-se efeito significativo da farinha de bandinha de feijão no aumento dos teores proteico e de fibras no snack obtido, quando comparada à farinha de quirera de arroz. Em relação às características tecnológicas do produto, obteve-se $0,17 \mathrm{~g} \cdot \mathrm{cm}^{-3}$ para densidade aparente, 7,75 para o índice de expansão e 435, g.f para a dureza instrumental. A formulação estudada foi aceita sensorialmente, com índice de aceitação para impressão global de $76 \%$. Conclui-se que é possível produzir snacks por extrusão a partir da incorporação de $30 \%$ de farinha de bandinha de feijão à farinha de quirera de arroz, resultando em produto aceito sensorialmente e com adequado valor nutricional.

Palavras-chave: Phaseolus vulgaris L.; Oryza sativa; Extrusão termoplástica; Propriedades tecnológicas; Avaliação nutricional; Aceitabilidade sensorial.

\section{Summary}

The objective of this work was to develop a new formulation for a snack made by thermoplastic extrusion from a mixture of broken rice flour and broken common bean flour, and assess the nutritional, sensory and technological potential of the new product. The broken common bean flour was added to the broken rice flour at a rate of $30 \%$, and the snack was produced in a pilot scale single screw extruder. The extrusion parameters were fixed using three extrusion zones (at 40,60 and $85{ }^{\circ} \mathrm{C}$ ); screw speed of $177 \mathrm{rpm}$; feed rate of $292 \mathrm{~g} \cdot \mathrm{min}^{-1}$; and a circular matrix with a diameter of $3.85 \mathrm{~mm}$. The snack sample was submitted to physicochemical, technological and sensory analyses. A significant effect of adding the broken common bean flour was observed in increasing the levels of protein and fiber in the snack, when compared with only broken rice flour. With respect to the technological characteristics, a bulk density of $0.17 \mathrm{~g} . \mathrm{cm}^{-3}$ was obtained, expansion rate of 7.75 and instrumental hardness of $435.98 \mathrm{~g}$.f. The formulation was well accepted, with an acceptance rate of $76 \%$ for overall impression. It was concluded that it was possible to produce extruded snacks by incorporating $30 \%$ of broken common bean flour into broken rice flour, resulting in gluten free products with good sensory acceptance and adequate nutritional value.

Key words: Phaseolus vulgaris L.; Oryza sativa; Thermoplastic extrusion; Technological characteristics; Nutritional evaluation; Sensorial acceptability. 


\section{Introdução}

O arroz (Oryza sativa) é um dos três cereais mais produzidos e consumidos no mundo, ficando atrás apenas do trigo e do milho (USDA, 2009). Dentre os cereais cultivados, é o que mais se destaca, por ser alimento básico da maioria da população, integrando a dieta de aproximadamente 2,4 bilhões de pessoas no mundo. É considerada uma cultura extremamente versátil, que se adapta a diferentes condições de solo e clima (LUZZARDI et al., 2005). Além disso, é um alimento de grande valor nutricional, altamente energético (ao redor de $90 \%$ de amido), rico em proteínas (7-8\%), sais minerais (fósforo, ferro e cálcio) e vitaminas do complexo $B$, especialmente o arroz tipo integral. A proteína, de alta qualidade, contém oito aminoácidos essenciais ao homem e encontra-se dispersa no endosperma e no farelo do grão, apresentando boa digestibilidade. Além disso, o arroz possui um baixo valor de lipídeos (BASSINELLO e CASTRO, 2004).

O feijão (Phaseolus vulgaris L.) é uma das principais fontes de proteína e um dos alimentos mais importantes para a população brasileira. Apresenta contribuição proteica média de $28 \%$ e possui em sua constituição todos os aminoácidos essenciais; é rico em lisina, mas limitante em aminoácidos sulfurados - metionina e cisteína (FONSECA MARQUES e BORA, 2000; PIRES et al., 2006). Por ser rico em lisina, o feijão melhora a qualidade das proteínas dos cereais da refeição, reconhecidamente deficientes nesse aminoácido (COELHO, 1991). Sendo assim, o feijão pode ser considerado complementar ao arroz, que é deficiente em lisina e relativamente rico em aminoácidos sulfurados. Segundo Teba et al. (2009), a mistura de feijão com arroz supre os aminoácidos essenciais e tem digestibilidade de $80 \%$.

Na indústria de beneficiamento de arroz, é comum a ocorrência de quebra de grãos, gerando um subproduto denominado quirera, constituído pelos grãos quebrados de menor tamanho; isso representa um problema econômico para a indústria arrozeira, pois este é rejeitado para consumo humano. No entanto, esse subproduto é uma fonte rica em amido, podendo-se elaborar uma farinha a ser explorada de forma eficiente na indústria de alimentos. No caso do feijão comum, existe também a formação de grãos quebrados, normalmente de cozimento difícil e, portanto, com baixo valor comercial, denominados vulgarmente de "bandinha de feijão"; esta, por sua vez, também pode ser transformada em farinha para fins alimentícios. Essas farinhas não contêm glúten, o que as torna interessantes para a elaboração de produtos alternativos aos celíacos ou intolerantes à proteína do glúten (SILVA e ASCHERI, 2009).

O processo de extrusão termoplástica, uma técnica de processamento de alimentos caracterizada por sua versatilidade, tem proporcionado numerosas aplicações
(FERNANDES et al., 2003) e começou a ser utilizada industrialmente com maior intensidade há pouco mais de duas décadas, a partir da década de 1990. Consiste em um processo térmico de curta duração que ocorre a temperaturas elevadas, em que materiais amiláceos e/ ou proteicos umedecidos são plasticizados e cozidos pela combinação de umidade, pressão, temperatura e cisalhamento mecânico, reestruturando as matériasprimas para criar novas formas e texturas, podendo melhorar as propriedades sensoriais, assim como a digestibilidade do material a ser extrudado (RIBAS, 2000; GUY, 2001; OLIVEIRA et al., 2004).

A extrusão permite ainda a obtenção de um efeito nutricional benéfico no produto, uma vez que viabiliza a mistura de diferentes matérias-primas e outros nutrientes (CARVALHO, 2000). Essa técnica permite maior facilidade na produção de misturas alimentícias destinadas ao consumo humano, produzindo uma variedade de produtos.

O objetivo deste trabalho foi desenvolver formulação de snack por extrusão termoplástica utilizando-se farinhas de quirera de arroz e de bandinha de feijão, além de avaliar o efeito da formulação nas características fisicoquímicas, nutricionais, tecnológicas e sensoriais do produto final.

\section{Material e métodos}

\subsection{Obtenção das farinhas}

As matérias-primas (quirera de arroz e farinha de bandinha de feijão carioca) utilizadas no processamento do snack foram adquiridas no comércio local de GoiâniaGO. A quirera de arroz e a bandinha de feijão foram trituradas em moinho de facas tipo Willye (TE-650 - Tecnal, Piracicaba-SP) até tamanho de partículas entre 9 e 20 mesh, e embaladas separadamente em sacos de polietileno com espessura de $0,15 \mathrm{~cm}$ e capacidade para $5 \mathrm{~kg}$ de material; esses sacos foram selados a quente e mantidos em temperatura de $5{ }^{\circ} \mathrm{C}$ por cerca de 30 dias, até o momento do processamento do snack.

\subsection{Caracterização granulométrica das farinhas}

Realizou-se, para ambas as farinhas, a análise granulométrica, utilizando-se classificador vibratório marca Produtest e conjunto de peneiras equivalentes a 9 , 20, 28, 35 mesh e uma base. O tempo estabelecido foi de 10 min, a uma intensidade de vibração correspondente à posição n 8 do reostato do aparelho (CARVALHO et al., 2010).

\subsection{Processamento do extrudado}

Inicialmente, foi realizado um planejamento experimental testando-se diferentes combinações de 
farinha de feijão, temperatura na terceira zona de extrusão e umidade de condicionamento das matérias-primas, otimizadas por meio de delineamento fatorial composto central rotacional de segunda ordem, tendo como respostas o teor de proteína, a densidade aparente e o índice de expansão radial. Em função dos resultados obtidos, procedeu-se a otimização do processo de extrusão para a produção do snack de farinhas de quirera de arroz e bandinha de feijão, sendo utilizados, neste trabalho, valores ótimos de teor de farinha de feijão (30\%), umidade (14\%) e temperatura na terceira zona de extrusão ( $85^{\circ} \mathrm{C}$ ) (CARVALHO et al., 2011 - no prelo).

Assim, a formulação do snack foi preparada adicionando-se $30 \%$ de farinha de bandinha de feijão e $70 \%$ de farinha de quirera de arroz, em peso. Adicionaram-se os seguintes temperos: $2 \%$ de cloreto de sódio, 0,7\% de glutamato monossódico, 0,2\% de pimenta do reino em pó, $0,2 \%$ de cominho em pó e $1,3 \%$ de alho granulado desidratado. A formulação foi condicionada para umidade igual a 14\%, base úmida, adicionando quantidade de água calculada de acordo com a Equação 1:

$Y=\left(U_{f}-U_{i}\right) \times P_{a} / 100-U_{f}$

em que: $Y$ = quantidade de água a ser adicionada $(\mathrm{mL})$; $U_{f}=$ umidade final da amostra; $U_{i}=$ umidade inicial $d a$ amostra; $\mathrm{P}_{\mathrm{a}}=$ peso da amostra $(\mathrm{g})$.

Após adição da quantidade de água necessária para se obter 14\% de umidade para a formulação, a mesma foi homogeneizada utilizando-se batedeira doméstica com agitação durante aproximadamente 15 min e, em seguida, armazenada à temperatura de $10{ }^{\circ} \mathrm{C}$ por $24 \mathrm{~h}$.

A amostra foi processada em extrusora monorrosca (Labor PQ30 - INBRAMAQ, Indústria de Máquinas Ltda., Ribeirão Preto-São Paulo), de configuração e parafuso intercambiáveis, com controle de temperatura nas diferentes zonas de aquecimento e velocidade do parafuso regulável por meio de regulador de frequência. Foram adotados os seguintes parâmetros: temperatura nas zonas do extrusor (Zona $1=40^{\circ} \mathrm{C}$; Zona $2=60^{\circ} \mathrm{C}$; Zona $3=85^{\circ} \mathrm{C}$ ), velocidade do parafuso (177 rpm), taxa de alimentação de $292 \mathrm{~g} \cdot \mathrm{min}^{-1}$ e matriz circular de $3,85 \mathrm{~mm}$. A temperatura de secagem, após o processo de extrusão, foi de $60^{\circ} \mathrm{C}$ em estufa com circulação de ar, durante 3 h. O snack obtido foi acondicionado em saco de polietileno $(24 \mathrm{~cm} \times 34 \mathrm{~cm} \times 0,15 \mathrm{~mm})$ e armazenado em local seco à temperatura ambiente para posterior realização das análises.

\subsection{Caracterização fisicoquímica das farinhas e do extrudado}

As farinhas de quirera de arroz e de bandinha de feijão, e o extrudado obtido foram caracterizados quanto a: umidade (HORWITZ, 1997); cinzas (HORWITZ, 1997); proteínas (HORWITZ, 1997); lipídeos (HORWITZ, 1997); fibra alimentar total (método enzimaticogravimétrico n 991.43 da HORWITZ, 1997); carboidratos (UNICAMP, 2006); valor energético total (USDA, 1963), e taninos, com extração segundo Bispo (1989) e quantificação pelo método colorimétrico de Folin-Denis $n^{\circ} 952.03$ da Horwitz (1997), fitato (HAUG e LANTZSCH, 1983) e aminoácidos totais (WHITE et al., 1986). Para o extrudado, determinou-se também a atividade de água em analisador de atividade de água (DECAGON, modelo Pawkit, Pullman, EUA).

\subsection{Caracterização tecnológica do extrudado}

Para a caracterização tecnológica do snack, foram realizadas análises de densidade aparente (RAMIREZ e WANDERLEI, 1997), índice de expansão radial - que representa a razão entre a expansão radial final do extrudado e o diâmetro da matriz do extrusor (foram analisadas dez amostras, as quais foram medidas após $30 \mathrm{~min}$ do processamento utilizando-se paquímetro digital, segundo metodologia de Alvarez-Martinez et al., 1988) - e textura instrumental. Foi medida a dureza utilizando-se texturômetro Stable Micro Systems modelo TA.XT Plus (Surrey, Inglaterra) com célula de carga de $50 \mathrm{~kg}$ e acessório de compressão cilíndrico de $2 \mathrm{~mm}$. As condições utilizadas neste experimento foram: velocidade de pré-teste, $1 \mathrm{~mm} . \mathrm{s}^{-1}$; velocidade de teste, 0,5 mm. $\mathrm{s}^{-1}$; velocidade pós-teste, $10 \mathrm{~mm} \cdot \mathrm{s}^{-1}$; distância percorrida pelo probe, $3 \mathrm{~mm}$. Para cada análise, realizaram-se dez repetições.

\subsection{Análise sensorial}

O snack extrudado foi avaliado quanto à aceitação, por meio de ficha sensorial utilizando-se escala hedônica estruturada de nove pontos ( 9 = gostei muitíssimo até 1 = desgostei muitíssimo) (STONE e SIDEL, 1993). A avaliação sensorial foi realizada por 100 provadores não treinados, de ambos os gêneros e faixa etária entre 19 e 59 anos, sendo funcionários, visitantes, alunos e estagiários da Embrapa Amazônia Oriental e da Universidade Federal do Pará. A amostra de snack foi apresentada aos potenciais consumidores à temperatura ambiente, em pratos plásticos descartáveis codificados com números aleatórios de três dígitos, e avaliada quanto a cor, sabor, textura, impressão global e intenção de compra (escala estruturada de cinco pontos ( 1 = certamente não compraria; 5 = certamente compraria). Calculou-se a porcentagem de aceitação de cada atributo sensorial considerando-se a nota 9 como 100\% de aceitação. Para a intenção de compra, a nota 5 foi considerada como 100\% de aceitação. 
Processamento e caracterização de snack extrudado a partir de farinhas de quirera de arroz e de bandinha de feijão CARVALHO, A. V. et al.

Os resultados das características avaliadas foram submetidos à análise de variância e as médias, quando significativas, comparadas pelo Teste de Tukey a 5\% de probabilidade, utilizando-se o software SAS ${ }^{\circledR}$ versão 8.0 (SAS, 1999).

\section{Resultados e discussão}

\subsection{Granulometria da matéria-prima}

Os resultados da análise granulométrica das farinhas de quirera de arroz e de bandinha de feijão, utilizadas na formulação do snack, estão apresentados na Tabela 1.

Observa-se que as farinhas de quirera de arroz e de bandinha de feijão ficaram retidas, com maior quantidade de partículas, na peneira de 20 mesh $(61,58$ e $84,23 \%$, respectivamente), evidenciando que as matérias-primas tiveram uma distribuição de partículas relativamente homogênea, estando em acordo com os resultados encontrados por Mendonça (2005) e Carvalho et al. (2010).

O tamanho de partícula das matérias-primas pode afetar notavelmente a textura e a uniformidade do produto final. É desejável que as partículas tenham tamanho e densidade uniformes para prevenir a segregação durante a mistura e o transporte antes do processo de extrusão. A importância da uniformidade das partículas também está relacionada com a uniformidade no condicionamento das mesmas; tal quesito baseia-se no princípio da difusividade da água, segundo o qual as partículas de menor tamanho serão as que mais rapidamente absorverão água em detrimento das demais. Se o tamanho das partículas da matéria-prima variar de forma significativa, o produto final poderá conter partículas indesejáveis com diferentes graus de cocção, resultando na diminuição da qualidade tanto na aparência como na palatabilidade do produto final (CARVALHO et al., 2009).

\subsection{Caracterização fisicoquímica das matérias-primas e do snack extrudado}

Os resultados das análises fisicoquímicas das farinhas de quirera de arroz e de bandinha de feijão, assim como do snack resultante da mistura de ambas, estão apresentados na Tabela 2.

Segundo Carvalho (2000), a composição centesimal das matérias-primas exerce grande influência na qualidade do produto final extrudado. Observa-se na Tabela 2 que a composição centesimal para a farinha de quirera de arroz ficou próxima aos dados reportados por Mendonça (2005), Silva et al. (2007) e Limberger et al. (2009), que relataram valores variando de 10,87-12,44\% para a umidade; 8,13-9,91\% para proteínas; 0,62-2,0 para lipídeos; 0,45-0,78\% para cinzas; 69,36-88,05\% para carboidratos e 0,74-2,13\% para fibras.

Com relação aos resultados do teor proteico da farinha de bandinha de feijão, verificou-se que o valor obtido está próximo aos observados por Pires et al. (2005), Rios et al. (2003) e Esteves (2000), que relataram teores entre 18 e 26\%. Para o teor de lipídeos, o valor encontrado está compreendido entre os resultados

Tabela 1. Análise granulométrica das farinhas de quirera de arroz e de bandinha de feijão.

\begin{tabular}{lccccc}
\multicolumn{1}{c}{ Farinha } & \multicolumn{5}{c}{ Tamanho das partículas (mesh) } \\
\cline { 2 - 6 } & $>\mathbf{9}$ & $\mathbf{9 - 2 0}$ & $\mathbf{2 0 - 2 8}$ & $\mathbf{2 8 - 3 5}$ & $<\mathbf{3 5}$ \\
Quirera de arroz (\%) & $0,00 \pm 0,00$ & $61,58 \pm 1,07$ & $37,01 \pm 0,17$ & $0,53 \pm 0,51$ & $0,87 \pm 0,50$ \\
Bandinha de feijão (\%) & $3,66 \pm 0,32$ & $84,23 \pm 0,55$ & $11,43 \pm 0,32$ & $0,23 \pm 0,06$ & $0,43 \pm 0,23$ \\
\hline
\end{tabular}

Tabela 2. Caracterização fisicoquímica de farinhas de quirera de arroz e de bandinha de feijão, e do snack extrudado, em base úmida.

\begin{tabular}{|c|c|c|c|}
\hline Determinação & Quirera de arroz & Bandinha de feijão & Snack \\
\hline Atividade de água & - & - & $0,34 \pm 0,01$ \\
\hline Umidade (\%) & $11,74 \pm 0,74$ & $10,84 \pm 0,05$ & $7,23 \pm 0,19$ \\
\hline Proteína (\%) & $7,50 \pm 0,20$ & $20,20 \pm 0,39$ & $11,27 \pm 0,34$ \\
\hline Lipídeos (\%) & $0,36 \pm 0,01$ & $0,88 \pm 0,03$ & $0,09 \pm 0,01$ \\
\hline Cinzas (\%) & $0,24 \pm 0,01$ & $3,79 \pm 0,12$ & $3,27 \pm 0,01$ \\
\hline Fibra alimentar total (\%) & $1,06 \pm 0,22$ & $17,02 \pm 0,92$ & $6,16 \pm 0,03$ \\
\hline Carboidratos totais (\%) & 80,16 & 64,29 & 78,14 \\
\hline Tiamina (mg.100 $\mathrm{g}^{-1}$ ) & $0,03 \pm 0,00$ & $0,45 \pm 0,00$ & $0,06 \pm 0,00$ \\
\hline Riboflavina (mg.100 g $\mathrm{g}^{-1}$ ) & $0,03 \pm 0,00$ & $0,15 \pm 0,00$ & $0,06 \pm 0,00$ \\
\hline Valor energético (kcal.100 g-1) & 349,64 & 277,80 & 333,81 \\
\hline Taninos (mg.100 g $\mathrm{g}^{-1}$ ) & $18,40 \pm 0,63$ & $461,37 \pm 10,86$ & $116,92 \pm 2,85$ \\
\hline Fitatos (mg.100 g-1) & $34,00 \pm 1,03$ & $399,25 \pm 13,26$ & $130,80 \pm 2,80$ \\
\hline
\end{tabular}


relatados por Maldonado e Sammán (2000) e Pires et al. (2005), que obtiveram teores variando de 0,54 a 1,29\%. Já para carboidratos, o valor observado está próximo ao relatado por Pires et al. (2005), que encontraram valores variando entre 68,92 e $76,75 \%$; para o teor de cinzas, o resultado verificado está compreendido na faixa observada por Pires et al. (2005) e Marzo et al. (2002), que encontraram de 2 a $4 \%$ para feijões do grupo carioca.

De acordo com os resultados (Tabela 2), observa-se que a farinha de bandinha de feijão se destacou nas frações de proteína, fibra alimentar e cinzas. Já a farinha de quirera de arroz, por ser constituída basicamente por endosperma amiláceo, apresentou na sua composição alto teor de carboidratos, embora o feijão também tenha apresentado teor elevado desse macronutriente. Esse fato está de acordo com Bassinello (2009; 2010), que relata os carboidratos como sendo os principais constituintes dos feijões, ocupando até $60 \%$ da sua composição total.

Embora o teor de umidade seja um parâmetro importante na conservação dos alimentos, em muitos casos a atividade de água tem sido o parâmetro preferido para ser medido e acompanhado, por representar melhor a água disponível ou o estado da água disponível que melhor se correlaciona com a conservação dos alimentos (CHIRIFE e BUERA, 1995). Com atividade de água de 0,34, observada neste trabalho, pode-se classificar o extrudado de arroz e feijão como alimento de baixa atividade de água. Os alimentos com teor baixo de água apresentam níveis de umidade inferiores a 20\% e atividade de água abaixo de 0,60, sendo, por isso, microbiologicamente estáveis, desde que não haja absorção de umidade durante a estocagem (MORITA et al., 2005).

Em relação à proteína, observou-se que a combinação das farinhas utilizadas resultou em um produto extrudado com teor proteico de $11,27 \%$, superior ao da farinha de quirera de arroz $(7,50 \%)$ e inferior ao da farinha de bandinha de feijão $(20,20 \%)$, porém superior ao resultado de 8,58\%, encontrado por Limberger et al. (2009) para salgadinhos extrudados de quirera de arroz. Dessa forma, fica evidenciado o incremento proteico que a utilização da farinha de bandinha de feijão proporcionou ao produto final e, portanto, a importância nutricional e potencial de aproveitamento desse subproduto no processamento de extrudados. Segundo Krause e Mahan (2005), produtos elaborados com misturas de proteínas em proporções adequadas têm sido desenvolvidos visando elaborar produtos que possam suprir as necessidades proteicas, principalmente de crianças e idosos.

Ainda com relação ao teor proteico, segundo a Resolução RDC n² 269, de 22 de setembro de 2005 (BRASIL, 2005), que trata do "Regulamento técnico sobre a ingestão diária recomendada (IDR) de proteína, vitaminas e minerais", a recomendação diária de proteínas estimada para crianças (4 a 6 anos) é de 19 g.dia ${ }^{-1}$ e, para adultos, $50 \mathrm{~g} \cdot$ dia $^{-1}$. De acordo com a Portaria $\mathrm{n}^{\circ} 33$ de 13 de janeiro de 1998, observa-se que o teor de proteínas $(11,27 \%)$ apresentado pelo snack de farinhas de quirera de arroz e de bandinha de feijão permite considerá-lo como fonte de proteínas para adultos e como um produto com alto teor de proteínas para crianças de 7 a 10 anos, pois atende às exigências de, no mínimo, 10 e 20\%, respectivamente, da IDR de referência por $100 \mathrm{~g}$ de alimento (BRASIL, 1998a; 2003).

Quando o snack de farinhas de quirera de arroz e de bandinha de feijão é comparado com produtos à base de milho comumente encontrados no mercado, observa-se que o produto obtido neste estudo apresenta um teor de proteínas mais elevado. Segundo Watson e Ramstad (1987), a composição média dos snacks de milho é de $6,3 \%$ de proteína, 53\% de carboidratos, 1,41\% de lipídeos e 1,9\% de cinzas.

Para a fibra alimentar, observou-se teor de 6,16\% no produto pronto para o consumo. Dessa forma, o snack produzido pode receber a alegação de alimento com alto teor de fibras (>6 g.100 g $\mathrm{g}^{-1}$ ), de acordo com a Portaria $n^{\circ}$ 27, de 13 de janeiro de 1998, da ANVISA (BRASIL, 1998b). Verifica-se ainda que o teor de fibras observado neste trabalho $(6,16 \%)$ é superior ao relatado por Menezes et al. (2001) para alguns cereais matinais, como cereal matinal de aveia, amêndoa e mel (4,90\%), cereal matinal de milho "Corn Flakes" (3,57\%) e cereal matinal de milho, trigo e aveia $(2,15 \%)$ e, próximo ao observado por Carvalho et al. (2009), estudando snacks de terceira geração obtidos a partir de farinhas de mandioca e pupunha, com teores variando de 4,93 a $6,22 \%$, em função da formulação testada.

O snack de farinhas de quirera de arroz e de bandinha de feijão apresentou valor calórico de $333,81 \mathrm{kcal} 100 \mathrm{~g}^{-1}$. Esse valor é considerado elevado, podendo o extrudado obtido ser empregado na alimentação como um produto energético, pois apresenta considerável teor de carboidrato. Além disso, o valor encontrado está próximo ao relatado por Martins (2009), que observou valor calórico de 361,68 kcal.100 g $\mathrm{g}^{-1}$ para snack à base de mandioca e camarão regional.

Para as vitaminas hidrossolúveis, tiamina e riboflavina, observaram-se teores no snack de 0,06 mg.100 $\mathrm{g}^{-1}$. O teor dessas vitaminas observado na matéria-prima e as condições de processamento utilizadas durante a extrusão, como a cocção que ocorre durante o processo, justificam esse valor reduzido. Além disso, segundo Ornellas (1995), o beneficiamento dos cereais retira a parte mais rica em vitaminas, sendo que o arroz polido é praticamente isento destas. Já para a tiamina, as perdas durante o cozimento ocorrem pela passagem da mesma para a água de cocção, pois ela é instável ao calor. Ainda segundo Ornellas (1995), a perda de tiamina é de 5 a 25\% em calor úmido. 
Processamento e caracterização de snack extrudado a partir de farinhas de quirera de arroz e de bandinha de feijão CARVALHO, A. V. et al.

Entre os fatores antinutricionais, o feijão comum contém principalmente taninos condensados, que são compostos fenólicos, e ácido fítico, que é a principal forma de armazenamento de fósforo (MARTINEZVALVERDE et al., 2000; MARTINEZ-DOMINGUEZ et al., 2002; SATHE, 2002). A ação antinutricional de taninos e fitatos está baseada na capacidade de formar complexos insolúveis com minerais, proteínas e amidos biologicamente indisponíveis para seres humanos, em condições fisiológicas normais (RICKARD e THOMPSON, 1997; MARTINEZ-VALVERDE et al., 2000; MARTINEZDOMINGUEZ et al., 2002). Entretanto, o ácido fítico e os compostos fenólicos, quando em baixas concentrações, apresentam também efeitos positivos sobre a saúde, como ação protetora frente ao câncer e prevenção de enfermidades cardiovasculares (SHAHIDI, 1997; MARTINEZ-DOMINGUEZ et al., 2002).

O snack apresentou 116,92 mg. $100 \mathrm{~g}^{-1}$ para taninos e 130,80 mg. $100 \mathrm{~g}^{-1}$ para fitatos. Observa-se ainda que, durante o processo de extrusão, ocorreu uma diminuição desses teores em relação às matérias-primas do produto, ainda que se atente para a porcentagem da farinha de bandinha de feijão ser menor (apenas 30\%) na farinha para obtenção do extrudado.

\subsection{Perfil de aminoácidos das matérias-primas e do snack extrudado}

A Tabela 3 apresenta a composição de aminoácidos das farinhas de quirera de arroz e de bandinha de feijão, e do snack delas produzido. Observa-se, para o snack, que os valores encontrados para todos os aminoácidos essenciais, com exceção dos aminoácidos sulfurados (metionina e cisteína) e lisina, foram superiores ao valor padrão de referência para crianças de 1 a 3 anos, estabelecido pelo Institute of Medicine of the National Academies (IMA, 2002).

Segundo Pires et al. (2006), uma proteína que apresenta escore químico maior que 1,0 para todos os aminoácidos é considerada de alto valor nutricional. Já o aminoácido que apresentar escore químico menor que 1,0, é chamado aminoácido limitante.

Os resultados encontrados para a composição de aminoácidos essenciais para a farinha de quirera de arroz estão de acordo com os relatados por Antunes et al. (1995). Em dietas à base de cereais, o aminoácido limitante presumível é a lisina (NAVES, 2007). Já Mendonça (2005) relatou, como aminoácidos limitantes na quirera de arroz, a lisina, a histidina e a treonina.

Tabela 3. Teor de proteína total (\%) e aminoácidos totais (mg.100 mg-1 de proteína) das farinhas de quirera de arroz e de bandinha de feijão, do snack produzido, do padrão de referência (IMA, 2002) e escore químico para o snack (EQ ${ }_{\text {snack }}$ ).

\begin{tabular}{|c|c|c|c|c|c|}
\hline \multirow[b]{2}{*}{ Aminoácidos } & \multicolumn{5}{|c|}{ Teor de aminoácidos (mg.100 $\mathrm{mg}^{-1}$ de proteína) } \\
\hline & $\begin{array}{c}\text { Farinha de } \\
\text { quirera de arroz }\end{array}$ & $\begin{array}{c}\text { Farinha de } \\
\text { bandinha de feijão }\end{array}$ & Snack & IMA $^{\mathrm{a}}$ & $\mathbf{E Q}_{\text {snack }}$ \\
\hline \multicolumn{6}{|l|}{ Essenciais } \\
\hline Treonina & $2,87 \pm 0,11$ & $3,90 \pm 0,04$ & $3,62 \pm 0,08$ & 2,7 & 1,34 \\
\hline Valina & $5,26 \pm 0,12$ & $4,79 \pm 0,04$ & $5,60 \pm 0,08$ & 3,2 & 1,75 \\
\hline Metionina & $2,27 \pm 0,01$ & $0,84 \pm 0,03$ & $1,57 \pm 0,02$ & $2,5^{\mathrm{b}}$ & $0,76^{b}$ \\
\hline *1/2 Cistina & $0,60 \pm 0,12$ & $0,22 \pm 0,01$ & $0,33 \pm 0,01$ & & \\
\hline Isoleucina & $3,58 \pm 0,01$ & $4,17 \pm 0,04$ & $4,37 \pm 0,08$ & 2,5 & 1,75 \\
\hline Leucina & $8,00 \pm 0,12$ & $7,98 \pm 0,07$ & $8,81 \pm 0,07$ & 5,5 & 1,60 \\
\hline Tirosina & $4,18 \pm 0,24$ & $3,37 \pm 0,04$ & $4,12 \pm 0,08$ & & \\
\hline Fenilalanina & $4,78 \pm 0,02$ & $5,59 \pm 0,04$ & $5,68 \pm 0,06$ & $4,7^{c}$ & $6,56^{c}$ \\
\hline Lisina & $2,75 \pm 0,12$ & $7,27 \pm 0,09$ & $4,78 \pm 0,02$ & 5,1 & 0,94 \\
\hline Histidina & $2,03 \pm 0,12$ & $2,97 \pm 0,01$ & $2,63 \pm 0,05$ & 1,8 & 1,46 \\
\hline Triptofano & $0,24 \pm 0,09$ & $0,44 \pm 0,04$ & $0,82 \pm 0,01$ & 0,8 & 1,03 \\
\hline \multicolumn{6}{|l|}{ Não essenciais } \\
\hline Arginina & $8,60 \pm 0,12$ & $7,01 \pm 0,04$ & $8,32 \pm 0,08$ & & \\
\hline Ácido aspártico & $8,00 \pm 0,01$ & $11,71 \pm 0,04$ & $10,79 \pm 0,33$ & & \\
\hline Serina & $4,66 \pm 0,12$ & $5,63 \pm 0,04$ & $5,60 \pm 0,16$ & & \\
\hline Ácido Glutâmico & $16,97 \pm 0,48$ & $14,50 \pm 0,02$ & $21,58 \pm 0,25$ & & \\
\hline Prolina & $4,30 \pm 0,12$ & $3,68 \pm 0,01$ & $4,28 \pm 0,08$ & & \\
\hline Glicina & $4,18 \pm 0,12$ & $3,86 \pm 0,01$ & $4,37 \pm 0,01$ & & \\
\hline Alanina & $5,38 \pm 0,12$ & $4,17 \pm 0,04$ & $5,19 \pm 0,02$ & & \\
\hline Proteína total (\%) & $8,37 \pm 0,22$ & $22,55 \pm 0,43$ & $12,14 \pm 0,36$ & & \\
\hline
\end{tabular}

*1/2 Cistina equivale a 1 cisteína. aPerfil de avaliação ( scoring pattern) para crianças de 1 a 3 anos (IMA, 2002, p. 10). ${ }^{b}$ metionina + cisteína. cfenialanina + tirosina. $\mathrm{EQ}=\left(\mathrm{mg} \text { aminoácido. } 100 \mathrm{mg}^{-1} \text { proteína }\right)_{\text {snack }} /\left(\mathrm{mg} \text { aminoácido.100 } \mathrm{mg}^{-1} \text { proteína }\right)_{\text {proteína padrão }}$. 
Com relação aos aminoácidos essenciais da farinha de bandinha de feijão, esse subproduto é constituído em maior parte por leucina, seguida por lisina, fenilalanina, valina, isoleucina, treonina, histidina e metionina. Essa composição é muito semelhante àquela observado em cultivares de feijão por Fonseca Marques e Bora (2000) e Ribeiro et al. (2007).

Nota-se, na Tabela 3, que o conteúdo de lisina foi 2,6 vezes maior na farinha de bandinha de feijão do que o encontrado na farinha de quirera de arroz; para o aminoácido metionina, observou-se o inverso, cujo conteúdo, na farinha de quirera de arroz, foi 2,7 vezes maior do que o encontrado na farinha de bandinha de feijão, comprovando que o feijão pode ser considerado complementar ao arroz, pois é deficiente em lisina e relativamente rico em aminoácidos sulfurados. Esse fato pode ser comprovado pelos resultados observados para o snack (Tabela 3), em que a mistura das farinhas de quirera de arroz e de bandinha de feijão proporcionou aumento para a maioria dos aminoácidos no snack, ultrapassando, com exceção da lisina e dos aminoácidos sulfurados, o valor recomendado pelo Institute of Medicine of the National Academies (IMA, 2002) para crianças de 1 a 3 anos.

Cintra et al. (2007), estudando os aminoácidos limitantes em uma dieta à base de arroz e feijão, observaram a treonina $(85,27 \%)$ e os aminoácidos sulfurados (92\%) como limitante primário e secundário, respectivamente. No presente trabalho, verificou-se que os aminoácidos limitantes para o snack foram a lisina e os sulfurados, que são também os aminoácidos limitantes no arroz e no feijão, respectivamente.

Em relação aos demais aminoácidos essenciais, o snack atingiu as necessidades requeridas para crianças de 1 a 3 anos, com destaque para os aminoácidos fenilalanina e tirosina que, juntos, apresentaram escore químico de 6,56. Lanfer Marques et al. (1997), em estudo com flocos de cereais de 13 diferentes marcas, encontraram em média 5,96 mg de fenilalanina. $100 \mathrm{mg}^{-1}$ de aminoácidos recuperados.

Souza (2003), estudando cereal matinal à base de castanha-do-brasil e farinha de mandioca, verificou perfil de aminoácidos inferior ao relatado neste trabalho para todos os aminoácidos, à exceção dos sulfurados, para os quais o autor verificou valor de 7,26 mg. $100 \mathrm{mg}^{-1}$; já para o triptofano, os valores foram muito próximos (0,85 mg.100 $\left.\mathrm{mg}^{-1}\right)$ ao encontrado no presente estudo $\left(0,82 \mathrm{mg} .100 \mathrm{mg}^{-1}\right)$.

\subsection{Caracterização tecnológica do snack extrudado}

A densidade aparente é uma forma indireta de quantificar a eficiência do processo de extrusão. De forma indireta, também permite avaliar objetivamente quão leves ou pesados são os extrudados elaborados e, assim, prever sua aceitabilidade pelo consumidor (CARVALHO et al., 2010). É uma importante característica dos produtos extrudados expandidos, na maioria das vezes, inversamente proporcional ao índice de expansão (WANG et al., 2007).

Pela densidade aparente, assim como o índice de expansão, busca-se descrever, de forma indireta, o grau de "transformação" do grânulo de amido e as variações de peso e volume que sofreu a massa amilácea ao sair do extrusor (CARVALHO et al., 2010).

A Tabela 4 apresenta os resultados das análises de densidade aparente, índice de expansão e dureza instrumental para o snack produzido.

Para a densidade aparente, o resultado encontrado no presente trabalho está de acordo com os relatados na literatura. Oliveira (2007) encontrou valores de densidade aparente entre 0,18 e 0,92 g. $\mathrm{cm}^{-3}$ para produtos extrudados de milho. Já Mendonça et al. (2005) observaram valores entre 0,14 e 0,68 g. $\mathrm{cm}^{-3}$ para extrudados elaborados com farinha de amaranto integral e quirera de arroz.

Gujska e Khan (1991) sugeriram que o grau de expansão afeta a densidade, a fragilidade e a textura dos produtos extrudados. Logo, o grau de expansão é um fator importante a ser monitorado na produção de snacks.

O índice de expansão do snack foi de 7,75, como mostra a Tabela 4, indicando que o produto apresentou adequada expansão. O valor encontrado foi superior aos observados por Borba et al. (2005) na extrusão de farinha de batata-doce, em que os autores relataram índices menores, variando de 1,8 a 2,6, e Mendonça (2005), que encontrou variação de 1,18 a 3,09 para produtos extrudados com farinhas de amaranto integral e quirera de arroz. Martins (2009), estudando snacks processados a partir de uma mistura binária de farinha de mandioca e camarão regional, obteve o valor de 4,13; Lustosa et al. (2010) verificaram variação de 3,29 a 4,56 para snacks de farinha de mandioca enriquecidos com caseína.

Ressalta-se que a expansão de materiais amiláceos é inversamente proporcional à umidade do material a ser extrudado. Segundo Ding et al. (2005), o aumento da umidade pode mudar a estrutura molecular da amilopectina do material amiláceo, reduzindo a viscosidade elástica e diminuindo, assim, a expansão do produto final. O snack produzido foi processado a uma

Tabela 4. Resultados das análises de densidade aparente, índice de expansão e dureza (valor médio e desvio padrão) para snack produzido.

\begin{tabular}{ccc}
$\begin{array}{c}\text { Densidade aparente } \\
\left(\mathbf{g} \cdot \mathbf{c m}^{-3}\right)\end{array}$ & $\begin{array}{c}\text { Índice de } \\
\text { expansão }\end{array}$ & $\begin{array}{c}\text { Dureza } \\
(\mathbf{g} \cdot \mathbf{f})\end{array}$ \\
\hline $0,17 \pm 0,00$ & $7,75 \pm 0,25$ & $435,98 \pm 75,52$ \\
\hline
\end{tabular}


umidade de $14 \%$, base úmida, a qual foi considerada adequada para proporcionar a expansão do produto final.

A dureza é um parâmetro de qualidade de grande importância na aceitação de produtos extrudados. É um parâmetro de textura que, fisicamente, representa a força necessária para produzir uma deformação, enquanto que, sensorialmente, representa a força requerida para a compressão de uma substância entre os dentes (MEILGAARD et al., 1999). A dureza é uma percepção do consumidor e está associada à expansão e à estrutura das células dos extrudados (DING et al., 2005).

O snack produzido apresentou dureza de 495,98 g.f. Esse valor está abaixo dos relatados por Mendonça et al. (1998) para snacks comerciais de milho (757,43 a 1210,17 g.f.), por Alves e Grossmann (2002) para snacks de farinha de cará $(757,43$ a 1210,7 g.f) e por Leonel et al. (2010) para snacks de farinha de soja e polvilho azedo (3580 a 5900 g.f). Ressalta-se que a dureza é um dos fatores que determinam a aceitabilidade do alimento pelo consumidor, assim como a fraturabilidade do produto (ALVES e GROSSMANN, 2002), sendo, por isso, desejável que seus valores sejam baixos. Porém, para essa propriedade de textura, não há definição da faixa de valores aceitáveis para snacks expandidos por extrusão (MENDONÇA et al., 1998).

Ding et al. (2005) relataram que a umidade foi o fator mais significativo a influenciar na expansão de extrudados à base de arroz e que um aumento no teor de umidade resultou em aumento de dureza. Além disso, os autores encontraram que uma elevação na temperatura de processo aumentou a crocância, ou seja, reduziu a dureza. O mesmo comportamento foi observado por Sebio e Chang (2000) na extrusão de farinha de inhame.

\subsection{Análise sensorial}

$\mathrm{Na}$ Tabela 5, observam-se os resultados das médias atribuídas pelos provadores para a avaliação sensorial do snack produzido e seu índice de aceitação.

De acordo com a Tabela 5, a textura destacou-se como o atributo com o maior índice de aceitação, atingindo 82,22\%. Hough et al. (2001) observaram que se outros atributos agradam ao consumidor, mas a textura ou a crocância não agrada, a rejeição ao alimento é imediata. Segundo os autores, para um produto sem crocância,

Tabela 5. Aceitabilidade sensorial do snack produzido.

\begin{tabular}{lcc}
\multicolumn{1}{c}{ Atributos } & $\begin{array}{c}\text { Médias } \pm \text { desvio } \\
\text { padrão }\end{array}$ & $\begin{array}{c}\text { Índice de } \\
\text { aceitação (\%) }\end{array}$ \\
\hline Cor & $6,13 \pm 1,52$ & 68,11 \\
Sabor & $6,78 \pm 1,69$ & 75,33 \\
Textura & $7,40 \pm 1,43$ & 82,22 \\
Impressão global & $6,83 \pm 1,35$ & 75,89 \\
Intenção de compra & $3,66 \pm 0,97$ & 73,20 \\
\hline
\end{tabular}

nem mesmo o adequado sabor pode aprová-lo. Em estudo sobre a avaliação sensorial de cereais matinais extrudados de castanha-do-brasil com mandioca, os autores observaram, para o atributo crocância, valor médio de 7,55, próximo ao relatado neste trabalho $(7,40)$; já para uma amostra de cereal matinal comercial, formulada à base de farelo de trigo, sabor levemente doce, adquirida no comércio local, os autores obtiveram nota média de 6,62 (SOUZA e MENEZES, 2006).

Nota-se que praticamente todos os atributos avaliados tiveram alta aceitabilidade, com índices de $75,33 \%$ para o sabor, $68,11 \%$ para cor e $75,89 \%$ para impressão global. O valor mais baixo para o atributo cor provavelmente seja por causa da coloração mais escura do produto final, em consequência do uso da farinha de bandinha de feijão na formulação, o que difere dos salgadinhos extrudados existentes no mercado.

Limberger et al. (2009), avaliando salgadinho extrudado de quirera de arroz, demonstraram elevado grau de aceitabilidade global, com 95\% dos provadores afirmando ter gostado muito do produto final. Já Alves e Grossmann (2002) obtiveram 80\% de aceitação para snack de farinha de cará.

Em estudo sobre a avaliação sensorial de cereais matinais extrudados de castanha-do-brasil com mandioca, os autores observaram notas médias variando de 7,22 a 7,88 para o sabor, em função da formulação, e 7,25 a 7,75 para a aceitação global. Já para o cereal matinal comercial formulado à base de farelo de trigo e adquirido no comércio local, os mesmos autores obtiveram nota média de 5,75 para o sabor e 5,70 para impressão global, valores inferiores ao verificado neste estudo (SOUZA e MENEZES, 2006).

A Figura 1 apresenta o histograma com a distribuição percentual da intenção de compra do snack produzido. Observa-se que 64\% dos provadores afirmaram que provavelmente ou certamente comprariam o produto se o encontrassem à venda, o que comprova a boa aceitabilidade do snack extrudado.

Verifica-se, também, o baixo nível de reprovação do produto final, sendo que, de 100 provadores, apenas três relataram que "certamente não comprariam" o snack de arroz e feijão. Observa-se ainda que o índice de rejeição do produto ficou abaixo do encontrado por Limberger et al. (2009), que observou 6\% dos provadores afirmando que "não comprariam" salgadinho extrudado de quirera de arroz. Souza e Menezes (2006), estudando extrudados a base de castanha-do-brasil e farinha de mandioca, verificaram notas médias para a intenção de compra variando de 3,95 a 4,63, em função da formulação do produto final; em comparação a um produto comercial à base de trigo, o valor foi de 3,02, inferior ao relatado pelos autores e ao encontrado neste trabalho $(3,66)$. 
Processamento e caracterização de snack extrudado a partir de farinhas de quirera de arroz e de bandinha de feijão CARVALHO, A. V. et al.

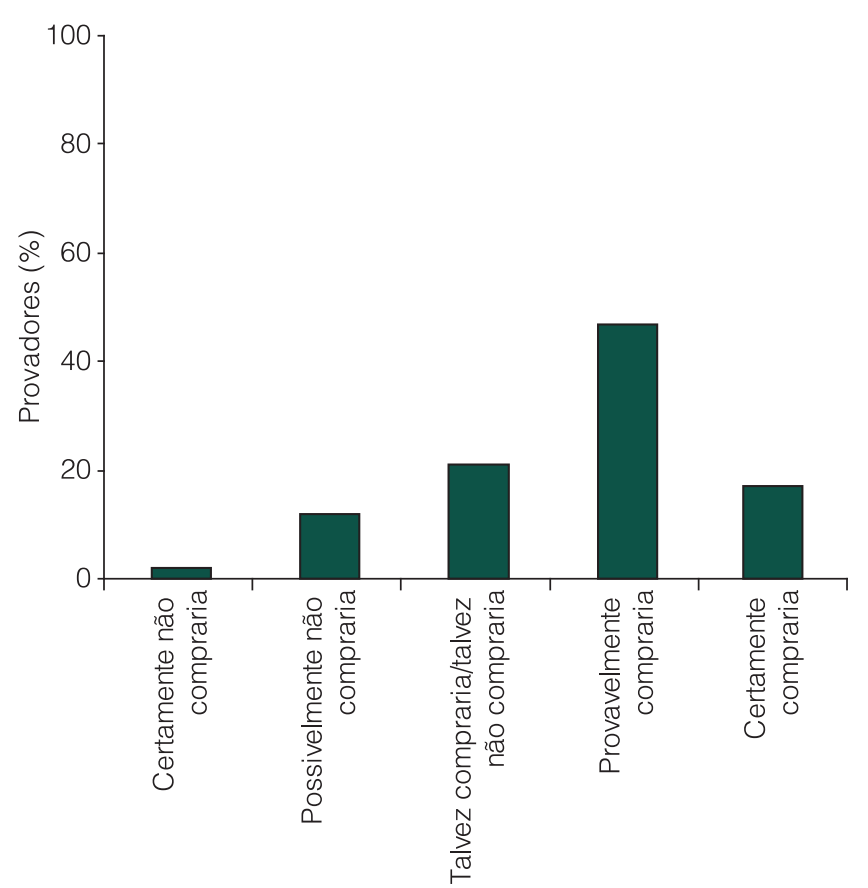

Figura 1. Distribuição percentual da intenção de compra do snack produzido.

É interessante ressaltar que, no presente estudo, $81 \%$ dos provadores tinham entre 20 e 30 anos, o que pode explicar, em parte, a grande aceitação do snack de arroz e feijão, visto que jovens, em geral, são os consumidores mais atraídos por tal tipo de produto.

\section{Conclusões}

É possível produzir snacks expandidos por extrusão a partir da incorporação de $30 \%$, em peso, de farinha de bandinha de feijão à farinha de quirera de arroz, com o produto final apresentando elevados índices de aceitação sensorial, alto índice de expansão e baixa densidade aparente.

A incorporação de farinha de bandinha de feijão ocasiona aumento nos teores de proteínas e fibra alimentar nos snacks estudados. O produto final obtido apresenta teor proteico de $11,3 \%$, o que permite considerá-lo como fonte desse nutriente para adultos. Com relação ao teor de fibras, o snack produzido pode receber a classificação de alimento com alto teor de fibras, de acordo com a legislação brasileira vigente.

\section{Referências bibliográficas}

ALVAREZ-MARTINEZ, L.; KONDURY, K. P.; HARPER, J. M. A general-model for expansion of extruded products. Journal of Food Science, Chicago, v. 53, p. 609-615, 1988. http://dx.doi. org/10.1111/j.1365-2621.1988.tb07768.x

ALVES, R. M. L.; GROSSMANN, M. V. E. Parâmetros de extrusão para produção de snacks de farinha de cará (Dioscorea alata). Ciência e Tecnologia de Alimentos, Campinas, v.
22, n. 1, p. 32-38, 2002. http://dx.doi.org/10.1590/S010120612006000200033

ANTUNES, P. L.; BILHALVA, A. B.; ELIAS, M. C.; SOARES, G. J. D. Valor nutricional de feijão rico 23, carioca, pirata-1 e rosinha-G2. Revista Brasileira de Agrociência, Pelotas, v. 1, n. 1, 1995.

BASSINELLO, P. Z. Qualidade nutricional, funcional e tecnológica do feijão. In: KLUTHCOUSKI, J.; STONE, L. F.; AIDAR, H. (Eds.). Fundamentos para uma Agricultura Sustentável, com Ênfase na Cultura do Feijoeiro. Santo Antônio de Goiás: Embrapa Arroz e Feijão, 2009. cap. 22, p. 385-424.

BASSinELlo, P. Z.; CASTRO, E. M. Arroz como alimento. Informe Agropecuário, Belo Horizonte, v. 25, n. 222, p. 101-108, 2004.

BASSINELLO, P. Z. Pós-produção, Qualidade dos Grãos de Feijão. Disponível em: <http://www.agencia.cnptia.embrapa. br/Agencia4/AG01/arvore/AG01_2_28102004161635.html>

Acesso em: 29 outubro 2010.

BISPO, E. S. Estudos de produtos industrializáveis de umbu (Spondias tuberosa, Arr. Câmara). 1989. 119 f. Dissertação (Mestrado em Tecnologia de Alimentos)-Faculdade de Engenharia de Alimentos, Universidade Federal do Ceará, Fortaleza, 1989.

BORBA, A. M.; SARMENTO, S. B. S.; LEONEL, M. Efeito dos parâmetros de extrusão sobre as propriedades funcionais de extrusados da farinha de batata-doce. Ciência e Tecnologia de Alimentos, Campinas, v. 25, n. 4, p. 835-843, 2005. http:// dx.doi.org/10.1590/S0101-20612008000300013

BRASIL. Ministério da Saúde. Agência Nacional de Vigilância Sanitária. Portaria n ${ }^{\circ}$ 33, de 13 de janeiro de 1998. Adota valores constantes de Tabelas do anexo desta portaria, como níveis de IDR para as vitaminas, minerais e proteínas. Diário Oficial da República Federativa do Brasil, Brasília, DF, 16 jan. 1998a. Disponível em: <http://www.anvisa.gov.br/legis/portarias/33_98. htm>. Acesso em: 05 maio 2011.

BRASIL. Ministério da Saúde. Agência Nacional de Vigilância Sanitária. Portaria $n^{\circ} 27$, de 13 de janeiro de 1998. (Aprova o Regulamento Técnico Referente à Informação Nutricional Complementar - Declarações Relacionadas ao Conteúdo de Nutrientes. Diário Oficial da República Federativa do Brasil, Brasília, DF, 1998b. Disponível em: <http://e-legis.anvisa.gov.br/ leisref/public/showAct.php?id=97>. Acesso em: 18 out. 2010.

BRASIL. Ministério da Saúde. Agência Nacional de Vigilância Sanitária. Resolução RDC n 359, de 23 de dezembro de 2003. Aprova Regulamento Técnico de Porções de Alimentos Embalados para Fins de Rotulagem Nutricional. Diário Oficial da República Federativa do Brasil, Brasília, DF, 26 dez. 2003. Disponível em: <http://e-legis.anvisa.gov.br/leisref/ public/ showAct.php?id=9058>. Acesso em: 22 nov. 2010.

BRASIL. Ministério da Saúde. Agência Nacional de Vigilância Sanitária. Resolução RDC n 269, de 22 setembro de 2005. 
Processamento e caracterização de snack extrudado a partir de farinhas de quirera de arroz e de bandinha de feijão CARVALHO, A. V. et al.

Aprova as categorias de Alimentos e Embalagens Dispensados e com obrigatoriedade de Registro. Diário Oficial da República Federativa do Brasil, Brasília, DF, 2005. Disponível em: <http:// www.anvisa.gov.br/alimentos/legis/especifica/regutec.htm> Acesso em: 18 out. 2010.

CARVALHO, R. V. Formulações de Snacks de Terceira Geração por Extrusão: Caracterização Texturométrica e Microestrutural. 2000. 89 f. Dissertação (Mestrado em Ciência de Alimentos)-Universidade Federal de Lavras, Lavras, 2000.

CARVALHO, A. V.; VASCONCELOS, M. A. M.; SILVA, P. A.; ASCHERI, J. L. R. Produção de snacks de terceira geração por extrusão de misturas de farinhas de pupunha e mandioca. Brazilian Journal of Food Technology, Campinas, v. 12, n. 4, p. 277-284, 2009. http://dx.doi.org/10.4260/BJFT2009800900022

CARVALHO, A. V.; VASCONCELOS, M. A. M.; SILVA, P. A.; ASSIS, G. T.; ASCHERI, J. L. R. Caracterização tecnológica de extrusados de terceira geração à base de farinhas de mandioca e pupunha. Ciência e Agrotecnologia, Lavras, v. 34 n. 4, p. 995-1003, 2010. http://dx.doi.org/10.1590/S141370542010000400028

CARVALHO, A. V.; RIOS, A. O.; BASSINELLO, P. Z.; SECCADIO, L. L. Otimização dos parâmetros tecnológicos para produção de snack extrudado a partir de arroz e feijão. Alimentos e Nutrição, Araraquara, 2011. No prelo.

CHIRIFE, J.; BUERA, M. P. A critical review of some non-equilibrium situations and glass transitions on water activity values of foods in the microbiological growth range. Journal of Food Engineering, Barking, v. 25, p. 531-552, 1995. http://dx.doi. org/10.1016/0260-8774(94)00033-6

CINTRA, R. M. G. C.; MAGALHÃES, C. O.; GARCIA, R. R.; MELLO, R.; PADILHA, A.; KUSAI, C.; CAETANO, L. Avaliação da qualidade da proteína de arroz e feijão e de dieta da região sudeste do Brasil. Alimentos e Nutrição, Araraquara, v. 18, n. 3, p. 283-289, 2007

COELHO, R. G. Considerações sobre as proteínas de feijão. Revista de Nutrição, Campinas, v. 4 (1/2), p. 122-145, 1991.

DING, Q.; AINSWOTH, P.; TUCKER, G.; MARSON, H. The effect of extrusion conditions on the physicochemical properties and sensory characteristics of rice based expanded snacks. Journal of Food Engineering, Oxford, v. 66, n. 3, p. 283-289, 2005. http://dx.doi.org/10.1016/j.jfoodeng.2004.03.019

ESTEVES, A. M. Comparação Química e Enzimática de Seis Linhagens de Feijão (Phaseolus Vulgaris L.). 2000. 55 f. Dissertação (Mestrado em Ciência de Alimentos)-Universidade Federal de Lavras, Lavras, 2000.

FERNANDES, M. S.; WANG, S. H.; ASCHERI, J. L. R.; OLIVEIRA, M. F.; COSTA, S. A. J. Effect of extrusion temperature in water absorption, solubility and dispersibility of pre-cooked cornsoybean (70:30) flours. Ciência e Tecnologia de Alimentos,
Campinas, v. 23, n. 2, p. 234-239, 2003. http://dx.doi. org/10.1590/S0101-20612003000200023

FONSECA MARQUES, M. F.; BORA, P. S. Composición química y análisis de aminoácidos de alubias. Ciencia y Tecnología Alimentaria, Madrid, v. 2, p. 248-252, 2000.

GUJSKA, E.; KHAN, K. Effect of temperature on properties of extrudates from starch fractions of navy, pinto and garbanzo beans. Journal of Food Science, Chicago, v. 55, n. 2, p. 466469, 1991. http://dx.doi.org/10.1111/j.1365-2621.1990.tb06788.x

GUY, R. Extrusión de los alimentos. Zaragoza: Acribia, 2001. $208 \mathrm{p}$.

HAUG, W.; LANTZSCH, H. Sensitive method for the rapid determination of phytate in cereal and cereal products. Journal of the Science of Food and Agriculture, Essex, v. 34, n. 12, p. 1423-1426, 1983. http://dx.doi.org/10.1002/jsfa.2740341217

HORWITZ, W. (Ed.). Official Methods of Analysis of the Association of Official Analytical Chemists. 16. ed. Gaithersburg: AOAC, 1997

HOUGH, G.; BUERA, M. P.; CHIHIRIFEH, J.; MORO, O. Sensory texture of commercial biscuits as a function of water activity. Journal of Texture Studies, Westport, v. 32, n. 1. p. 57-74, 2001. http://dx.doi.org/10.1111/j.1745-4603.2001.tb01034.x

INSTITUTE OF MEDICINE OF THE NATIONAL ACADEMIES - IMA. Protein and amino acids. In: INSTITUTE OF MEDICINE OF THE NATIONAL ACADEMIES. Dietary Reference Intakes for Energy, Carbohydrate, Fiber, Fat, Fatty Acids, Cholesterol, Protein, and Amino Acids. Washington: The National Academies Press, 2002. part 2, cap. 10, p. 72

KRAUSE, M. V.; MAHAN, L. K. Alimentos, Nutrição e Dietoterapia. 11.ed. São Paulo: Roca, 2005. 1242 p.

LANFER MARQUEZ, U. M.; NISHI, L. E.; BARROS, R. M. C.; FILISETTI COZZI, T. M. C. C.; PENTEADO, M. V. C. Estudo da composição química de flocos de cereais com ênfase nos teores de fenilalanina. Ciência e Tecnologia de Alimentos, Campinas, v. 17, n. 3, p. 314-319, 1997. http://dx.doi.org/10.1590/S010120611997000300023

LEONEL, M.; MARTINS, J. C.; MISCHAN, M. M. Produção de snacks funcionais à base de farinha de soja e polvilho azedo. Ciência Rural, Santa Maria, v. 40, n. 6, p. 1418-1423, 2010. http://dx.doi.org/10.1590/S0103-84782010000600027

LIMBERGER, V. M.; COMARELA, C. G.; PATIAS, L. D.; BRUM, F. B.; EMANUELLI, T.; SILVA, L. P. Produção de salgadinho extrusado de quirera de arroz para uso na indústria de alimentos. Ciência Rural, Santa Maria, v. 39, n. 9, p. 2590-2594, 2009. http://dx.doi.org/10.1590/S0103-84782009000900032

LUSTOSA, B. H. B.; LEONEL, M.; MISCHAN, M. M. Parâmetros de extrusão na produção de snacks de farinha de mandioca enriquecidos com caseína. Ciências Agrárias, Londrina, v. 31 , n. 1, p. 109-126, 2010. 
Processamento e caracterização de snack extrudado a partir de farinhas de quirera de arroz e de bandinha de feijão CARVALHO, A. V. et al.

LUZZARDI, R.; SARAIVA, C. T.; BOCK, F.; WEBER, L.; PASQUALLI, L. Avaliação preliminar da produtividade em campo e qualidade industrial de híbridos de arroz no Rio Grande do Sul. In: CONGRESSO BRASILEIRO DE ARROZ IRRIGADO, 4., 2005, Santa Maria. Anais... Santa Maria: Sociedade Sul-Brasileira de Arroz Irrigado, 2005. p. 70-72.

MALDONADO, S.; SAMMÁN, N. Composición química y contenido de minerales de leguminosas y cereales producidos en el noroeste argentino. Archivos Latinoamericanos de Nutrición, Caracas, v. 50, n. 2, p. 195-199, 2000.

MARTINEZ-DOMINGUEZ, B.; IBAÑEZ, M. B.; RINCÓN, F. Acido fítico: aspectos nutricionales e implicaciones analíticas. Archivos Latinoamericanos de Nutrición, Venezuela, v. 52 , n. 3, p. 219-231, 2002.

MARTINEZ-VALVERDE, I.; PERIAGO, M. J.; ROS, G. Significado nutricional de los compuestos fenólicos de la dieta. Archivos Latinoamericanos de Nutrición, Venezuela, v. 50, n. 1, p. $5-18,2000$

MARTINS, L. H. S. Estudo da Extrusão Termoplástica de uma Mistura Binária à Base de Farinha de Mandioca (Manihot esculenta Crantz) e Camarão Regional (Macrobrachium Amazonicum). 2009. 150 f. Dissertação (Mestrado em Ciência e Tecnologia de Alimentos)-Faculdade de Engenharia de Alimentos, Universidade Federal do Pará, Belém, 2009.

MARZO, F.; ALONSO, R.; URDANETA, E.; ARRICIBITA, F. J.; IBÁÑES, F. Nutritional quality of extruded kidney bean (Phaseolus vulgaris, L. var. Pinto) and its effects on growth and skeletal muscle nitrogen fractions in rats. Journal of Animal Science, Champaing, v. 80, n. 8, p. 875-879, 2002.

MEILGAARD, M.; CICILLE, G. V.; CARR, B. T. Sensory Evaluation Techniques. 3. ed. Boca Raton: CRC Press, 1999. $387 \mathrm{p}$.

MENDONÇA, S.; KARAM, L. B.; GROSSMANN, M. V. E. Análise instrumental de textura e sua correlação com a avaliação sensorial em "snacks" comerciais. CONGRESSO BRASILEIRO DE CIÊNCIA E TECNOLOGIA DE ALIMENTOS,16., 1998. Rio e Janeiro. Anais... Rio de Janeiro: SBCTA, 1998, v. 1, p. 84-87.

MENDONÇA, X. M. F. D. A Extrusão Termoplástica no Desenvolvimento de Produtos Derivados de Amaranto e Arroz. 2005. $182 \mathrm{f}$. Tese (Doutorado em Tecnologia de Processos Químicos e Bioquímicos)-Escola de Química, Universidade Federal do Rrio de Janeiro, Rio de Janeiro, 2005.

MENEZES, E. W.; CARUSO, L.; LAJOLO, F. M. Avaliação da qualidade dos dados de fibra alimentar. Estudo em alimentos brasileiros. In: LAJOLO, F. M.; SAURA-CALIXTO, F.; PENNA, E. W.; MENEZES, E. W. (Eds.). Fibra dietética en Iberoamerica: Tecnología y salud. 2. ed. São Paulo: Varela, 2001. cap. 11, p. 165-178.

MORITA, A. S.; GOIS, V. A.; PRAÇA, E. F.; TAVARES, J. C.; ANDRADE, J. C.; COSTA, F. B.; BARROS JÚNIOR, A. P.;
SOUSA, A. H. Cristalização de melão pelo processo lento de açucaramento. Ciência Rural, Santa Maria, v. 35, n. 3, p. 705-708, 2005. http://dx.doi.org/10.1590/S0103-84782005000300035

NAVES, M. M. V. Características químicas e nutricionais do arroz. Boletim do Centro de Pesquisa e Processamento de Alimentos, Curitiba, v. 25, n. 1, p. 51-61, 2007.

OLIVEIRA, G. D. Obtenção de Produtos Extrusados Expandidos e não Expandidos de Casca de Soja e Milho. 2007. 106 f. Dissertação (Mestrado em Ciência e Tecnologia de Alimentos)-Universidade Federal Rural do Rio de Janeiro, Rio de Janeiro, 2007

OLIVEIRA, M. F.; WANG, S. H.; COSTA, P. S.; ASCHERI, J. L. R. Qualidade de cozimento de massas de trigo e soja pré-cozidas por extrusão. Pesquisa Agropecuária Brasileira, Brasília, v. 39, n. 5, p. 501-507, 2004

ORNELLAS, L. H. Técnica Dietética: Seleção e Preparo dos Alimentos. 6. ed. São Paulo: Atheneu, 1995, p. 191-194.

PIRES, C. V.; OLIVEIRA, M. G. A.; CRUZ, G. A. D. R.; MENDES, F. Q.; MENDES, F. Q.; REZENDE, S. T.; MOREIRA, M. A. Composição físico-química de diferentes cultvares de feijão (Phaseolus vulgaris L.). Alimentos e Nutrição, Araraquara v. 16, n. 2, p. 157-162, 2005.

PIRES, C. V.; OLIVEIRA M. G. A.; ROSA, J. C.; COSTA, N. M. B. Qualidade nutricional e escore químico de aminoácidos de diferentes fontes protéicas. Ciência e Tecnologia de Alimentos, v. 26, p. 179-187, 2006. http://dx.doi.org/10.1590/S010120612006000100029

RAMIREZ, J. L. A.; WANDERLEY, C. P. Effect de los parametros de extrusion, caracteristicas de pasta y textura de pellets (snacks de terceira generacion) producidos a partir de trigo y maiz. Alimentaria, Madrid, v. 279, n. 1, p. 93-98, 1997.

RIBAS, A. I. et al. Métodos Experimentales en la Ingeniería de los Alimentos. Zaragoza: Acribia, 2000. 292 p.

RIBEIRO, N. D.; LONDERO, P. M. G.; CARGNELUTTI FILHO, A.; JOST, E.; POERSCH, N. L.; MALLAMANN, C. A. Composição de aminoácidos de cultivares de feijão e aplicações para o melhoramento genético. Pesquisa Agropecuária Brasileira, Brasília, v. 42, n. 10, p. 1393-1399, 2007.

RICKARD, S. E.; THOMPSON, L. U. Interactions and biological effects of phytic acid. In: SHAIDI, F. (Ed.). Antinutrients and Phytochemicals in Food. Washington: Division of Agricultural and Food Chemistry American Society, 1997. p. 294-312.

RIOS, A. O.; ABREU, C. M. P.; CORRÊA, A. D. Efeito da estocagem e das condições de colheita sobre algumas propriedades físicas, químicas e nutricionais de três cultivares de feijão (Phaseolus vulgaris, L.). Ciência e Tecnologia de Alimentos, Campinas, v. 23, p. 39-45, 2003. Suplemento. http:// dx.doi.org/10.1590/S0101-20612003000400008 
Processamento e caracterização de snack extrudado a partir de farinhas de quirera de arroz e de bandinha de feijão CARVALHO, A. V. et al.

SATHE, S. K. Dry Bean Protein Functionality. Critical Reviews in Biotechnology, Inglaterra, v. 22, n. 2, p. 175-223, 2002.

SEBIO, L.; CHANG, Y. K. Effects of selected process parameters in extrusion of yam flour (Dioscorea rotundata) on physicochemical properties of the extrudates. Nahrung, Weinheim, v. 44, n. 2, p. 96-101, 2000.

SHAHIDI, F. Beneficial health effects and drawbacks of antinutrients. In: SHAIDI, F. (Ed.). Antinutrients and Phytochemicals in Food. Washington: Developed from a symposium sponsored by the Division of Agricultural and Food Chemistry American Society, 1997. p. 1-9.

SILVA, R. F.; ASCHERI, J. L. R.; PEREIRA, R. G. F. A. Composição centesimal e perfil de aminoácidos de arroz e pó de café. Alimentos e Nutrição, Araraquara. v.18, n. 3, p. 325-330, 2007.

SILVA, R. F.; ASCHERI, J. L. R.; Extrusão de quirera de arroz para uso como ingrediente alimentar. Brazilian Journal of Food Science and Technology, Campinas, v. 12, n. 3, p. 190-199, 2009. http://dx.doi.org/10.4260/BJFT2009800900012

SOUZA, M. L. Processamento de Cereais Matinais Extrusados de Castanha-do-Brasil com Mandioca. 2003, 191 f. Tese (Doutorado em Tecnologia de Alimentos)-Faculdade de Engenharia de Alimentos, Universidade Estadual de Campinas, Campinas, 2003.

SOUZA, M. L.; MENEZES, H. C. Avaliação sensorial de cereais matinais de castanha-do-brasil com mandioca extrusados. Ciência e Tecnologia de Alimentos, Campinas, v. 26 , n. 4, p. 950-955, 2006. http://dx.doi.org/10.1590/S010120612006000400036
STONE, H. S.; SIDEL, J. L. Sensory Evaluation Practices. 2. ed. San Diego: Academic Press, 1993. 338p.

TEBA, C. S.; ASCHERI, J. L. R.; CARVALHO, C. W. P. Efeito dos parâmetros de extrusão sobre as propriedades de pasta de massas alimentícias pré-cozidas de arroz e feijão. Alimentos e Nutrição, Araraquara, v. 20, n. 3, p. 411-426, 2009.

UNIVERSIDADE ESTADUAL DE CAMPINAS - UNICAMP. Tabela Brasileira de Composição de Alimentos - TACO. Versão 2. 2. ed. Campinas: UNICAMP/NEPA, 2006. Disponível em: <www.unicamp.br/nepa/taco/>. Acesso em: 20 out. 2010.

UNITED STATES DEPARTAMENT OF AGRICULTURE - USDA. Composition of Foods. Washington: Agricultural Research Center Service, 1963. 190 p. (Agriculture handbook, n. 8).

UNITED STATES DEPARTAMENT OF AGRICULTURE - USDA. Foreign Agricultural Service. Production, Supply and Distribution Online: Custom Query. USDA, 2009. Disponível em: <http://www.fas.usda.gov/psdonline/psdQuery.aspx>. Acesso em: 15 de janeiro de 2009.

WANG, J.; JING, Z.; YUAN, X. Preparation of resistant starch from starch-guar gum extrudates and their properties. Food Chemistry, London, v. 101, n. 1, p. 20-25, 2007. http://dx.doi. org/10.1016/j.foodchem.2006.01.005

WATSON, S. A.; RAMSTAD, P. E. (Ed.). Corn: Chemistry and Technology. Sant Paul: American Association of Cereal Chemist, 1987. 605 p.

WHITE, J. A., HART, R. J., KRY, J. C. An evaluation of the Waters Pico-Tag system for the amino acid analysis of food materials. Journal Automatic Chemistry, London, v. 8, p. 170-177, 1986. http://dx.doi.org/10.1155/S1463924686000330 